\title{
Qualitative research and evidence-based dentistry: linking evidence to practice
}

\section{Tim Newton}

Senior Lecturer in Psychology in Relation to Dentistry, Department of Dental Public Health and Oral Health Services Research, Guy's, King's and St Thomas' Dental Institute, London, UK

Qualitative research has made a limited impact upon the dental literature. A review of the 18216 articles published over 5 years (1996-2000) in the 37 journals listed in the Science Citation Index for Dentistry, Oral Surgery and Medicine revealed that only $15(<0.1 \%)$ articles adopted qualitative methods. The contribution of qualitative methods to the evidence base of dentistry to date therefore has been small. In this paper, I explore the relationship between evidence-based dentistry and qualitative methodology. I propose that qualitative methods provide a useful technique for exploring the diffusion of evidence into clinical practice: they should be added to the toolbox of approaches to evidence-based dentistry.

It may at first appear that the relationship between qualitative research and evidence-based dentistry is an uneasy one. Qualitative research could be construed as lacking the scientific rigour necessary for the proper appraisal of clinical interventions, the basis of evidence-based dentistry, regardless of the rigorous criteria by which qualitative research should be judged. ${ }^{1}$ Evidence-based dentistry has its roots in the discipline of clinical epidemiology, whereas qualitative methods have their foundations in the social sciences. The two methodologies should be viewed as complementary, however, each addressing a particular type of research question.

The process through which evidence is transformed into treatment recommendations is established, ${ }^{2}$ but scientists are beginning to understand that the transformation of evidence-based recommendations into clinical practice is challenging. ${ }^{3}$ It is a process that itself requires research. It is the contention of this paper that qualitative research techniques provide a tool for identifying the relevant dimensions in this process as a result of key assumptions that underlie the qualitative approach. Green and Britten ${ }^{4}$ list five characteristics that are the basis of qualitative research. They comprise:

- Naturalism

- Interpretation

- Process

- Interaction

- Relativism

I shall use these characteristics as a structure upon which to build the case for qualitative methods as a link between evidence and practice.

\section{Naturalism}

Qualitative methods seek to understand health and health-related behaviour in its everyday or 'natural' context. This necessarily involves exploring the com- plexity of behavioural contexts, including barriers to health-care behaviours, and the antecedents and consequences of behaviour. For example, take selection of treatment for a patient. Clinical trials adopt a systematic approach to the question of treatment choice. The patient is randomly assigned to a treatment condition. The treatment (or lack of) is performed to a set level, which is monitored. In the more natural settings of general dental practice, clinical decision-making is more complex and is likely to be influenced by many factors, only one of which is the availability of evidence of best practice. Qualitative studies are a useful first step in teasing out the complex dimensions that influence treatment choice. One important component may be the influence of the dentist/patient interaction (see below).

Interpretation

Qualitative methods seek to identify subjective meanings of a phenomenon, eg. how patients make sense of such objective variables as the findings from studies of fluoridation, and the relative merits of various treatment options. Two studies in the UK have examined the public's understanding and perceived role in advocating fluoridation. The findings revealed that the public is influenced by many factors other than the evidence of benefit. Hastings et $a l^{5}$ suggest that members of the public are unlikely to advocate water fluoridation 
because of the low priority given to oral health, and because water is as an emotive topic. Furthermore, in focusgroup discussions Lowry et $a l^{6}$ found that the general public wishes to be informed of plans to fluoridate water, but that members of the public did not perceive themselves as the appropriate people to judge the effectiveness of such interventions. These findings provide an insight into the general public's view of water fluoridation - those interested in advocating water fluoridation to the public should recognise that lack of information is less important than the perception that the public is not wellplaced to make such choices.

An exploration of the subjective meaning of health-related phenomena need not be restricted to understanding patients' health-related behaviours. Health care professionals also use inferential techniques to make sense of objective data. For example, clinicians will weight evidence from various sources and use heuristic techniques to summarise data. These processes will have implications for their understanding of research findings and therefore diffusion into practice. ${ }^{7,8}$

\section{Process}

Qualitative methods have been used to identify the social processes that underlie health care. An excellent example of such research is provided by Kay and Blinkhorn. ${ }^{7}$ Content-analysis of indepth interviews with 20 general dental practitioners revealed that an understanding of disease processes and of available treatment options was an insufficient basis for treatment decision-making. Many considerations outside concepts of health were brought to bear on the decisions made by the dental practitioner and patient, such as the impact of disease and treatment upon work and social interactions.

\section{Interaction}

Qualitative studies often take interactions as their focus. For example, in medicine, the encounter between physician and patient has been viewed as bringing together potentially conflict- ing views of health and illness which require negotiation in order to achieve desired outcomes. ${ }^{9}$ Adopting such a framework allowed Britten et $a l^{10}$ to identify misunderstandings between the doctor and patient which led to errors in drug prescription. There have been no published qualitative studies of the dentist/patient interaction to date.

\section{Relativism}

Qualitative research is relativist. It focuses on different explanatory frameworks without making judgements about the value of the different systems. For example, research examining the oral health-related behaviour of minority ethnic communities seeks to identify the place of this behaviour in its social and cultural context: for an excellent example of such an approach see Kwan and Williams. ${ }^{11}$ Such an approach adopts the viewpoint that social and cultural beliefs are of equal validity as beliefs about health. Neither is given precedence.

The implementation of evidencebased practice in dentistry will depend critically upon an understanding of the process of the diffusion of knowledge from centres of research to general dental practice. It will be important to understand the context of general dental practice and the influence of factors other than evidence upon treatment-choice, eg. the interaction of dental practitioner and patient. Inherent in such an approach is the assumption that an understanding of the context of general practice is as important as an understanding of the evidence in determining the process of diffusion. Qualitative methods provide a rigorous approach to understanding this process. The adoption of qualitative methodologies does not imply the rejection of the quantitative methods appropriate to evidencebased practice, but instead acknowledges that different research questions call for the adoption of different research methodologies.

1. Mays N, Pope C. Assessing quality in qualitative research. BMJ 2000; 320:50-52.
2. Hamer S, Collinson G. Achieving Evidencebased Practice: a Handbook for Practitioners. London: Tindall, 1999.

3. NHS Research Development Programme. Methods to Promote the Implementation of Research Findings in the NHS: Priorities for Evaluation. Leeds: Department of Health, 1995.

4. Green J, Britten N. Qualitative research and evidence-based medicine. BMJ 1998; 316:1230-1232.

5. Hastings $G B$, Hughes $K$, Lawther S, Lowry RJ. The role of the public in water fluoridation: public health champions or anti-fluoridation freedom fighters? Br Dent J 1998; 184:39-41.

6. Lowry RJ, Thompson B, Lennon MA. How much do the general public want to be involved in decisions on implementing water fluoridation? Br Dent J 2000; 188:500-502.

7. Kay EJ, Blinkhorn AS. A qualitative investigation of factors governing dentists' treatment philosophies. Br Dent J 1996; 180:171-176.

8. Nordenram $G$, Norberg A. Ethical issues in dental management of patients with severe dementia: ethical reasoning by hospital dentists. A narrative study. Swed Dent J 1998; 22:61-76.

9. Barry CA, Bradley $C P$, Britten N, Stevenson FA, Barber N. Patients' unvoiced agendas in general practice consultations: qualitative study. BMJ 2000; 320:1246-1250.

10. Britten N, Stevenson FA, Barry CA, Barber $\mathrm{N}$, Bradley CP. Misunderstanding in prescribing decisions in general practice: a qualitative study. BMJ 2000; 320:484-488.

11. Kwan SY, Williams SA. Dental beliefs, knowledge and behaviour of Chinese people in the United Kingdom. Community Dent Health 1999; 16:33-39.

\section{Commentary}

This article makes the very important point that the process of translating evidence-based recommendations into clinical practice requires research. This need is receiving recognition from diverse fields within health care, such as primary care, ${ }^{1}$ health management ${ }^{2}$ and acute care. ${ }^{3}$ The massive response to evidence-based health care can be attributed to the fact that health is a biomedical science, and the evidencebased approach provides a framework for using science to improve the quality of care. Health care is also a social science, which means that clinical encounters, doctor/patient relationships, relationships with colleagues and the patient's daily life are all factors that 
greatly influence whether practitioners and patients adopt evidence. ${ }^{4}$

The framework used by the author is helpful for explaining the principles of qualitative research, but it now needs to be applied to the field of dentistry. The concept of naturalism, for example, can be applied to issues such as dental hygiene. Dental health is influenced by the patient's socio-economic situation and social networks. Qualitative research could be used to explore this broader 'natural' context, producing findings useful for creating prevention strategies that are more relevant and feasible to people in their daily lives. Interactions between dentist and patient provide another potentially fruitful area for qualitative research. The author points out that there are no publications exploring the interaction between patient and dentist, to date. There is, however, a large literature on the quality of doctor/patient communication and implications for decisionmaking in other health care settings, with methods that could be easily carried over into dental research., ${ }^{5,6}$ If dentist/patient communication was explored qualitatively, the findings could illuminate the epidemiology of dentistry, providing explanations for such phenomena as the uptake of dental services and the ability to follow dental advice.

The article alludes to the challenges of implementing evidence from clinical trials in real life, an issue increasingly being researched in other settings. ${ }^{7}$ There is mounting recognition that evidence from trials is only one piece of the clinical picture, which must be balanced by social, political and economic considerations. Qualitative research is uniquely placed to provide knowledge of these other spheres, and can be used in conjunction with clinical evidence to link research to practice.

\section{Janet Harris}

Director, Health Sciences, University of Oxford, Oxford, UK
1. Greenhalgh T, Worrall JG. From EBM to CSM: the evolution of context-sensitive medicine. J Eval Clin Prac 1997; 3:105-108.

2. Fitzgerald L, Ferlie E, Wood M, Hawkins C. Evidence into practice? An exploratory analysis for the interpretation of evidence. In Organisational Behaviour in Health Care: The Research Agenda. Edited by Mark AL, Dopson S. London: Macmillan Press, 1999.

3. Evans D, Haines A (Eds). Implementing Evidence-based Changes in Health Care. Abingdon: Radcliffe Medical Press, 2000.

4. Greenhalgh T, Hurwitz B. Narrative-based Medicine: Dialogue and Discourse in Medical Practice. London: BMJ Books, 1998.

5. Charles C, Gafini A, Whelan T. Shared decision making in the medical encounter: what does it mean? (Or it takes two to tango). Soc Sci Med 1997; 44:681-962.

6. Britten N, Stevenson FA, Barry CA, Barber $\mathrm{N}$, Bradley CP. Misunderstandings in prescribing decisions in general practice: a qualitative study. BMJ 2000; 320:484-488.

7. Fairhurst K, Huby G. From trial data to practical knowledge: qualitative study of how general practitioners have accessed and used evidence about statin drugs in their management of hypercholesterolaemia. BMJ 1998; 317:1130-1134. 